\title{
Improving innovation as a factor in influencing the sustainable development of society
}

\author{
Sergey Efimushkin ${ }^{l}$, Anna Efimushkina ${ }^{2}$ \\ ${ }^{1}$ Candidate of Economic Sciences, assistant professor of the department "Industrial logistics" Bauman \\ Moscow State Technical University, BMSTU; \\ ${ }^{2}$ Assistant of the department of Public Health, health and hygiene the Peoples' Friendship University \\ of Russia, RUDN, Moscow
}

\begin{abstract}
The article, on the basis of domestic and foreign experience, the problems of possible limitations in the short term, natural resources, as well as the possibility of increasing the effectiveness of the solution of global problems of natural resources and sustainable development of society by improving innovation, creating natural-like technology, the convergence of technological innovation, organizational transformation and designing new business models. The examples of the development of innovative technologies, the creation of technical equipment and their practical use in the interaction of universities and industrial enterprises are considered. The possibilities of increasing synergies through the use of business incubators, science and technology parks, technology clusters as well as partnerships between universities and industrial enterprises are considered. The foreign experience and successful domestic experience of innovative activity of the regions confirming the prospects of creating innovative territories of priority development using the integration of scientific, educational and industrialentrepreneurial activities of various forms of organization and support of innovative activities are presented. The analysis of the competencies and characteristics of an engineer-entrepreneur necessary for successful work in the modern conditions of an innovative economy is carried out, as well as recommendations for the successful formation of the required competencies and characteristics.
\end{abstract}

Keywords: life activity, convergence, nature-like technologies, synergy, technology cluster, business incubator, technology park, partnership, university, industrial enterprises, entrepreneurship.

\section{Introduction}

Throughout the history of mankind, the sustainability of the society development is ensured by the creation and implementation of new ideas, more efficient sources of power, based on more advanced technologies that require better organization and quality management. Achieving sustainable development of society is the global and permanent goal of human society. The absolute majority of states, including the Russian Federation, on the recommendation of the United Nations, adopted the basic principle of sustainable development of society, according to which civil society and the state take responsibility for ensuring the ability to meet the needs of both present and future generations. 
The state of sustainable development is associated with the consumption of various natural resources, including energy. Mankind has created an economic model in which production, in fact, is a machine for the destruction of resources. And when a large part of the globe, including India and China, was involved in the globalization process, everyone saw a "bottom" in this model, a resource collapse came. In fact, the machine for the destruction of resources in today's technological order is still valid. For example, over the past 100 years, the amount of oxygen scorched in the atmosphere corresponds to what has happened in nature for hundreds of millions of years. If the trend continues, then we will return to primitive existence, through a series of wars for access to resources. An alternative to this is to create a nature-like technological structure, to return technology inside a closed resource cycle of nature and create a fundamentally new base for the innovative development of society. What factors can influence this process in our opinion? Using the decomposition method, we single out the most significant ones and consider them both individually and in integration aspects.

\section{Convergence of science and technology}

The Russian research center Kurchatov Institute considers the convergence of science and technology as the basis of a new technological structure, the purpose of which is to reproduce wildlife systems. Convergence means not only mutual influence, but also the interpenetration of technologies when the boundaries between individual technologies are erased and many interesting results arise precisely in the framework of interdisciplinary work at the intersection of regions [1]. At the initial stage of innovative development, the use of NBIC technologies is expected. This is nano, bio, information and cognitive sciences. Nanotechnology is the technology of creating any material by atomic or molecular manipulation. Biotechnologies introduce the biological, biotechnological part, i.e. the ability to create a hybrid. Then, IT technology turns this hybrid into an intelligent system with the help of microelectronics. At these junctions, tools and developments of one area are used to advance another. Of the four described areas (nano-, bio-, info-, cogno-) the most developed (information and communication technologies) at the moment most often provides tools for the development of others. In particular, this is the possibility of computer simulation of various processes. [2] The nature-like technologies created in this way, based on the reproduction of living processes, provide uniquely new opportunities in the widest range of their applications - in the quality of life, in all areas of medicine, in energy, etc.

The idea that in the future humanity will be able to create any objects by assembling them "molecule by molecule", or even "atom by atom", belongs to Nobel Prize winner, professor of the California Institute of Technology Richard Feynman. "By learning to manipulate individual atoms, mankind will be able to synthesize anything. Not a single physical or chemical law prevents us from changing the mutual position of atoms...." [3], i.e. use atoms as ordinary building material. Even today, fundamental research in the field of chemical technology has allowed us to obtain nanocrystalline and supermicrocrystalline materials with a complex of special properties. They can be successfully used in extreme operating conditions - at low temperatures, high loads and aggressive environments. Based on them, high-strength and ultralight metal-polymer composites can be created for use in catalysts and filter elements, in medicine for the manufacture of corrosion-resistant implants. Detailed research on the results and prospects of using nanotechnology in technology are given under the guidance of A.A. Abrahamyan in the monograph [4].

Nanotechnology products, created on the basis of the optimal assembly of atoms and molecules, make it possible to obtain extremely high characteristics. Japanese scientists from the University of Tokyo Seikei managed to create a microscopic «eternal bearing» in which friction losses are close to zero, and synthetic molecules - «fullerenes» served as material for 
it. These achievements of nanotechnology can be used in the production of wear-free, almost eternal nanorobots designed to solve a wide range of problems, including the diagnosis and treatment of diseases, including the fight against aging, the restructuring of the human body "on order», the manufacture of heavy-duty structures, etc. [5] In the future, nanotechnology will lead to the emergence and development of a new industry - nanobiology: a set of technologies that allow controlling biological processes at the molecular level. [6]

Convergence reaches its maximum effect as part of interdisciplinary work at the intersection of areas, as a result of the interaction and interpenetration of technologies. And in this regard, the search for new organizational forms for creating and supporting innovative activities is of particular importance.

\section{Partnership of universities and industrial enterprises}

The most important feature of the modern innovation paradigm is that in the modern world, innovation is systemic. They include all the variety of connections carried out as part of the interaction between universities and industrial enterprises. The development of modern technologies and the creation of new materials today are impossible without interdisciplinary fundamental research focused on solving applied problems, without the cooperation of leading scientific schools and industrial enterprises.

There is a long history of partnerships between universities and industry in research and development and the impact of this on local and national economies. Partnership in research and development is a decisive factor in the field of world competitiveness. The example of the United States with its most successful scientific and industrial economy is a proof of this. "The ability of the United States to excel in the development of all new high-tech sectors is usually explained by the scientific base and institutional advantages of the partnership between universities and industry, as well as mutually beneficial interests in the commercialization of research results" [7].

In this kind of partnership, the university has special advantages: the integrated nature of scientific research and the synergy effect in the interaction of various research areas and developments. On the other hand, when working with industrial enterprises, attention is focused on the commercialization of R\&D results, and the possibilities for entrepreneurial activity are expanded with the involvement of university employees and students. For example, the interdisciplinary nature of scientific research conducted at the Bauman Moscow State Technical University and extensive partnerships with industrial enterprises make it possible to diversify the developed technologies. Such interaction often leads to qualitatively new achievements in the creation of high technology and new generation technology. Scientists of BMSTU developed a number of plasma-optical technologies based on the use of high-intensity continuous-spectrum UV radiation generated by plasma of high-power pulsed discharges [8]. Using traditionally strong ties with industrial companies, as well as partnerships with leading organizations of the sanitary-epidemiological, environmental and biomedical profile, scientists were able to establish a number of application areas of new technologies, for each of which the corresponding technical equipment was designed.

The analysis of world and domestic experience shows that such interaction is most effectively carried out in the framework of partnerships between the university - business state. Commercialization of scientific research results and knowledge through effective management of innovation and technology transfer should be a priority for all university and state research institutes.

An example of a successful partnership of university with industrial enterprise to solve problems of improving the efficiency of environmental management is the Research Triangle Science Park (North Carolina, USA). [9] The park's activities have led to structural changes in the state's economy, increasing the scientific potential of its universities and the education 
system as a whole. A global brand of the region emerged as the leader in creating high technology and innovation. The experience of the Research Triangle has become a model for regional and industry communities seeking leadership in creating high technology and innovation. The creation of this center reflects the main goals for the development of innovation and cooperation to enhance the welfare of the region. [10]

Such an experience is not unique; it largely coincides with the model of creating an innovative region implemented in recent years in Linkoping (Sweden). Linkoping is an example of the practical implementation of the triple helix model. [11]

The transition to a knowledge-based society is the basic premise of the triple helix model. If in the USA there were traditionally established "university - business" relations at the beginning, and then the state appeared as a supplier of resources, in Sweden universities connected to the classical double spiral "state - business", creating a new institutional structure of a post-industrial, knowledge-based society. At one time, the joint work of the industrial business represented by the Saab Company and the state in the field of innovative technologies led to the creation of a new type of university in Linkoping. In addition to traditional academic functions, educational activities and scientific research, the university took on additional tasks to stimulate the creation of new enterprises and innovative development of the region. Thus, the university has become the main driver of the growth of the entrepreneurial and knowledge-based environment.

A special place in the innovative development of Israel is occupied by its oldest university in Haifa and the Technion called the Israel Silicon Valley. [12] Here, local start-ups interact with world leaders - Microsoft, Intel, Google, Yahoo, and IBM; here, the Technion finds students, researchers, and carriers of business projects. $75 \%$ of Israeli engineers left the walls of its faculties, laboratories and research centers.

Today, in terms of the number of high-tech companies, Israel is approaching the level of Silicon Valley in the United States. The government actively supports modern research and development, as well as international scientific and economic projects. [13]

\section{Innovative development of territories, cluster strategy}

Technological innovations cannot develop effectively without innovations in other areas. In fact, innovations in the field of creating new business models, optimizing processes and organizational transformations together with the creation of competitive technologies are the most important conditions in solving global problems of life in modern society. Thus, the need arises to create organically interacting blocks: the legislative framework, a venture financing network, the infrastructure for creating and supporting innovative activities (business incubators, science parks, technology transfer centers, etc.). The block approach should also include the formation of innovative territories with technological clusters developed in them.

The cluster strategy is based on special competitive advantages, which are due to the presence of a concentration of enterprises in similar or related industries. So the influence of the synergetic effect of both regional and sectoral interaction of enterprises is affected. Clusters unite not only production and commercial structures; their participants also are scientific organizations, universities, government bodies and institutions supporting innovation. [14]

Innovation orientation is an important distinguishing feature of the cluster. In the formation of such innovative zones, it is necessary to master not only the technology of creating their individual components, but also the technology of creating a synergistic interaction between them, an innovative inter-corporate culture, which turns them from the mechanical combination of many independently existing elements into a single creature capable of solving problems at a much higher regional level. [15] 
The creation of technological clusters is essential in the successful innovative development of the region: as a network of organizations united by a single material, financial and information flows, carrying out a full cycle of the innovation process. The totality of the above structures allows us to talk about the territory of priority development, which serves as a tool to reduce the innovation cycle due to the joint work of various science park structures and as a result, the rapid promotion of ideas arising in the field of science to the production sphere and turning them into goods.

According to Harvard Business School professor M. Porter, "acting "regionally" is not a matter of tactics, it is a matter of survival in the future" [16]. However, the creation of one type of science park structures is not enough for the full development of the region. Separately, research, technological and industrial parks can successfully implement only one of innovation process stages: to promote commercialization, transfer or implementation of technologies in production, respectively. In addition, harmonization of all elements and participants in innovation is needed.

Foreign experience and successful domestic experience of innovation in the regions of the Russian Federation confirm the prospects of creating innovative territories of priority development using the integration of scientific, educational and industrial-entrepreneurial activities using various forms of organization and support of innovation [17]. A successful example of such integration can be Nanocenter-Dubna established on the basis of the Joint Institute for Nuclear Research and the special economic zone Dubna. Nanocenter includes: a business incubator in the field of nanotechnology, a technology transfer center, a center for the collective use of equipment and a venture fund to provide funding in the early stages of innovation projects. [18]

The Special Economic Zones in Dubna, Zelenograd, Kazan, Tomsk and other cities have all the necessary basic conditions for this and demonstrate the advantages of the cluster approach and synergetic interaction in solving the global problems of modern society: sustainable development and increasing the level of its vital activity. However, it is necessary to make changes in the training of a specialist, to pay special attention to the development of creativity and instilling an entrepreneurial spirit, which will significantly increase the potential opportunities of both innovative companies and the region as a whole.

Studies conducted in various countries confirm a close correlation between commitment to hierarchical power and innovation potential. It is noted that the higher the importance of the hierarchy in the country, the lower the innovative potential. Today, the activities of a specialist are closely connected with innovation; the creation of new jobs and is carried out mainly through the formation of new enterprises. New qualities of an engineer are increasingly appreciated: imagination, creativity, ability and taste for innovation. In new management models the entrepreneur is increasingly confident in the central place. [19]

Initiative, entrepreneurial qualities are not included today among the fundamental values of the education system. It gives each student more and more scientific and technological knowledge and information, but does not give approaches to the evolution of imagination, bold innovations, a taste of risk, a sense of team spirit practice and creative activity. One cannot hope to educate entrepreneurs without being able to get involved in entrepreneurship already in the learning process. The leading role in this belongs to technical universities. For the formation of a modern specialist, it is necessary to base on the integration of the educational and scientific process and production; in addition, an innovative entrepreneurial environment must be created at the university, in which the future engineer can be formed. [20]

The leading engineering school of France, École de Minnes, at one time attempted to reform the training of an engineer. This reform was implemented in École de Minnes, Ales (EMA). Its goal is to create a model of a new type engineer: "engineer-entrepreneurhumanist", an engineer who is able to innovate and create social and economic wealth 
through creative thinking. An entrepreneurial engineer is an engineer who has the ability to create new projects and new activities within an existing industrial group, or in the structure of a small or medium-sized enterprise, or by creating his own enterprises for this purpose. First of all, he is an engineer with a strong scientific and technical culture, but also with the ability to use his innovations in economic activities [21].

\section{Conclusions}

Ensuring the sustainable development of society and solving the most important problems of human life today is impossible without interdisciplinary basic research aimed at creating a nature-like technological structure, without the cooperation of leading scientific schools and industrial enterprises. Such interaction often leads to qualitatively new achievements in the creation of high technology and new generation technology. Nature-like technologies based on the reproduction of living processes provide uniquely new opportunities in a wide range of applications. The convergence of science and technology means not only mutual influence, but also interpenetration, when the boundaries between individual technologies are erased, and many interesting and important results are achieved at the intersection of areas. And in this regard, the search for new organizational forms for creating and supporting innovative activities is gaining importance. The analysis of world and domestic experience shows that innovative interaction is most effectively carried out in the framework of partnerships: university - business - state. Commercialization of research results through effective management and technology transfer using the advantages of a cluster strategy for the innovative development of the territory should be a priority for all university and state research institutes. Moreover, special attention should be paid to raising the level of culture and attitude towards innovation and entrepreneurship even at the stage of specialist training, not only through the integration of scientific and educational activities, but also through the creation of a scientific and entrepreneurial environment at the university. As experience shows, the creation of business incubators, technology parks and other forms of increasing the activity of relations with business and local authorities contributes to this.

\section{References}

1. Roco M., Bainbridge W. (eds) 2004. Converging Technologies for Improving Human Performance: Nanotechnology, Biotechnology, Information Technology and Cognitive Science. Arlington: Kluwer Academic Publisher.

2. Borner K. 2006. Mapping the Structure and Evolution of Science. Knowledge in Service to Health: Leveraging Knowledge for Modern Science Management.

3. R. Feynman There's plenty of room at the bottom. Engineering and Science, 1960 P. 22-36

4. A.A. Abrahamyan, I.I. Balabanov, V.I. Beklemishev et al. Fundamentals of Applied Nanotechnology. Magistr-Press, Moscow. 2007. p. 83-95

5. Freitas R. 2006. Economic Impact of the Personal Nanofactory. Nanotechnology Perceptions: A Review of Ultraprecision Engineering and Nanotechnology 2: P.111126

6. Freitas R. 1998. Exploratory Design in Medical Nanotechnology: A Mechanical Artificial Red Cell, Artificial Cells, Blood Substitutes and Immobilization. Biotechnology. 26: 411 -430. http://www.rfreitas.com/

7. Leher M., Asakawa K. Pushing Scientists into the Marketplace: Promoting Sciens Entrepreneurship. Management Review. Vol 46, 2004, 55-75. 
8. A.S. Kamrukov, N.P. Kozlov, High-intensity plasma-optical technologies for solving urgent environmental and biomedical problems. Safety in the Technosphere Journal, No. $3,2009$.

9. Research Triangle Science Park website: wwwHYPERLINK «http://www.rtp.org/».HYPERLINK g

10. J. Hardin "North Carolina Research Triangle Park. History, success factors and lessons learned", 2005

11. http://liu.se/artikel/integritetspolicy-liu

12. S.N. Efimushkin, G.A. Sazhaeva, An innovative way to develop the Israeli economy. Economics Journal, No. 4, 2016, p.387-396

13. Cukierman E., Rouach D. Le bouclier technologique de l'innovation. Pearson France, 2013.

14. O. V. Matveeva, V.L. Vasilenok. The role of clusters in the development of the economy. 2013, Economic Sciences, 99. 101-103

15. O.V. Nesmachnykh, V.V. Litovchenko, The nature of the occurrence of the synergistic effect in the industrial cluster and the assessment of its impact, 2014, Scientific Review. Series 1: Economics and Law, 1, 27-35.

16. Porter, Harvard University, Research Triangle. Clusters of Innovation Initiative

17. V.V. Ivanov, B.I. Petrov, K.I. Pletnev, Territories of high concentration of scientific and technological potential in the EU countries, Innovative development of territories in Russia and the EU, Tacis 4, SkanruS, Moscow, 2001.

18. OEZ Dubna, www.dubna.rosoez.ru

19. I. Dubina, Personnel creativity management in an innovative economy, ACADEMIA, Moscow. 2009. Pp. 130-134

20. S.N. Efimushkin, Innovative production and management problems, Collection of scientific papers of the VII international conference on controlling Problems in the economy, organization of production and management, Moscow, 2019

21. S.N. Efimushkin, A. Dorizon, Experience in training an engineer-entrepreneur in France, Journal of Management and Business Administration, No. 2, 2010, P.173-179 